\title{
Anonimato e resistência em eles eram muitos cavalos, de Luiz Ruffato
}

Ivete Lara Camargos Walty I PUC Minas

Resumo: Análise do livro eles eram muitos cavalos, de Luiz Ruffato, em seu diálogo com a história da literatura brasileira, a partir da relação entre anonimato, exclusão social, lixo e vida urbana.

Palavras-chave: Anonimato, Exclusão social, Lixo, Vida urbana.

romance eles eram muitos cavalos, de Luiz Ruffato, desde o título, retirado do Romanceiro da Inconfidência, de Cecília Meireles, conforme já muito comentado, é marcado pelo anonimato. Tal anonimato atravessa várias instâncias da(s) narrativa(s), ela(s) mesma(s) destituída(s) de nome(s). É sobre esse processo que pretendo discorrer, evidenciando as relações entre diversos níveis do enunciado e da enunciação a partir da tríade texto, intertexto e contexto.

Ao intitular seu livro com um verso do poema narrativo publicado por Cecília Meireles em 1953, Ruffato (re)ativa uma constelação de sentidos, atravessada por elementos históricos, míticos, sociopolíticos e existenciais. Importa ressaltar algumas das conexões dessa constelação, aí incluindo o diálogo com a história da literatura brasileira, ela mesma, no dizer de Maria Eunice Moreira, "desalojada enquanto gênero narrativo, desajustada na sua relação com o ideal 
político que a elegeu como mecanismo mais promissor e abalada pela noção de construção, como artefato da linguagem (...)".

Ruffato, retomando e grafando com letras minúsculas um verso do romance LXXXIV, intitulado "dos Cavalos da Inconfidência", reforça a relação cavalos/ cavaleiros já inscrita no poema-base, associando-o à população desnomeada que habita as grandes cidades. A epígrafe acrescenta outros versos que reforçam tal associação:

Eles eram muitos cavalos, mas ninguém mais sabia os seus nomes, sua pelagem, sua origem... (Cecília Meireles)

Vale retomar ainda o início da estrofe de onde foi retirada essa epígrafe, ajuntando a essa relação a idéia de morte, jugo e violência:

Eles eram muitos cavalos.

E morreram por esse montes, esses campos, esses abismos, tendo servido a tantos homens. ${ }^{2}$

No próprio poema em que canta os heróis da Inconfidência Mineira, Cecília Meireles, retomando um gênero medieval, por si só já híbrido, ${ }^{3}$ introduz um episódio que é lido por Ruffato como o canto àqueles que não foram e não são nomeados na história do Brasil e na história da literatura brasileira. É justamente esse processo de desnomeação que indica um caminho de leitura do livro de Ruffato, ele mesmo desnomeado enquanto gênero, na medida em que mistura

1. MOREIRA, 2003, p. 62.

2. MEIRELES, 1972 , p. 228.

3. Romance deve ser entendido, nesse caso, como um gênero de origem medieval, muito característico na península Ibérica, constituído de narrativas breves, sob forma de poemas épico-líricos, que originalmente eram cantados ao som de um instrumento, celebrando as aventuras e proezas de um herói de cavalaria ou fatos da nacionalidade de um povo. Preservadas pela memória popular, oralizados de forma fragmentária pelo povo, algumas ações mudavam de natureza e tomavam vida independente: ao lado das imagens objetivas e da narração, peculiares ao gênero épico-lírico, no qual se impõem notas de emoção e subjetividade, e o gênero dramático-lírico, no qual predominam os diálogos. Etimologicamente, o termo origina-se do latim romanice, ou seja, as narrativas eram feitas no loqui romanice (falar à maneira de Roma). 9http://www.suigeneris.pro.br/literatura_romanceiro.htm 
gêneros discursivos diversos: cartas, hagiologia, horóscopo, recados de secretária eletrônica, ofertas de emprego, anúncios de serviços sexuais, lista de livros, orações, simpatias populares, cardápios, relatos de fatos do cotidiano doméstico e urbano, pequenas notas jornalísticas, monólogos.

A organização textual reforça a impossibilidade de classificação do livro e do seu objeto: os sujeitos reificados, em sua mobilidade, pelo menos aparente, pela cidade.

Essa reificação, já indiciada pelo poema que dá nome ao livro, reforçase por meio de uma segunda epígrafe: "Até quando julgareis injustamente, sustentando a causa dos ímpios?", retirada do salmo 82, intertexto que, aposto ao texto de Ruffato, abre mais um nó da conexão, o universo bíblico, ratificando a idéia de anonimato e desamparo, conforme se vê por outros versículos do mesmo salmo, que se refere à injustiça e à parcialidade dos juízes:

Fazei justiça ao fraco e ao órfão, procedei retamente para com o aflito e o desamparado. Socorrei o fraco e o necessitado; tirai-o das mãos dos ímpios. Eles nada sabem, nem entendem; vagueiam em trevas; vacilam todos os fundamentos da terra. (v.3-5)

Nessa epígrafe, figura um interlocutor - Vós - que não deixa de remeter ao leitor do livro de Ruffato, aí incorporado como narratário. O texto bỉblico, deslocado, perde sua função primeira de evangelização, como ocorre também com o episódio "Leia o salmo 38" (p.73), em que imperativamente se recomenda a leitura do salmo com função de simpatia ou de corrente para se alcançar alguma graça:

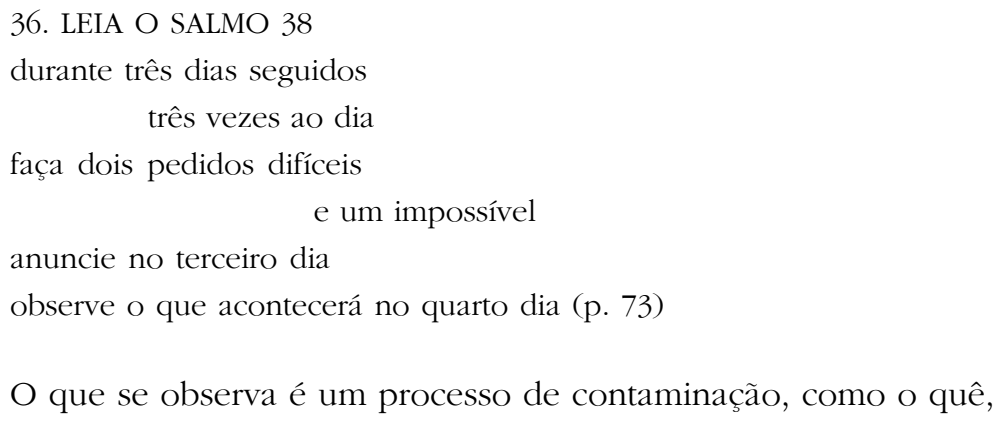
curiosamente, é previsto no próprio salmo em sua proposição de arrependimento do pecador: "Tornam-se infectas e purulentas as minhas chagas"por causa da minha loucura (v. 5) "Os meus amigos e companheiros afastam-se da minha praga; e os meus parentes ficam de longe." (v.11). 
Contaminação e deslocamento são, pois, dois mecanismos básicos da construção do(s) texto(s) de Ruffato, que, associados à violência, promovem uma leitura da sociedade contemporânea. Por isso mesmo, nos enunciados, a presença do lixo, dos excrementos, em ambiente escatológico, expõe, em sua mistura, a montagem de um outro texto, o das relações sociais e culturais.

Daniel Castillo-Durante, em seus estudos sobre alteridade nas relações culturais, provocadas e/ou acentuadas pelas ondas migratórias, faz um elogio do anônimo, mostrando-o, paradoxalmente, como uma forma de escape às representações do mesmo.

O Autor, associando anonimato e máscara, afirma que se trata de um paradoxo que confunde a ligação entre o sujeito e seu desejo. Referindo-se então ao anonimato como a parte escondida da alteridade, recorre à etimologia da palavra anônimo:

A palavra vem do latim anonymus. Trata-se de um empréstimo do grego nomos que quer dizer nome e lei ao mesmo tempo. O a privativo poderia então enviar tanto à ausência de patrônimo quanto a um estatuto de fora-do-jogo. O anônimo escaparia assim ao emaranhado das filiações metendo-se ao abrigo da lei. Nesse contexto, a alteridade ganharia ao ser tematizada como uma cartografia possível de estratégias permitindo subtrair-se às representações do mesmo.

O anônimo seria, assim, uma força que viria abalar o sistema constituído, abrindo "um espaço alternativo de alteridade frente ao lado preconstruído, anquilosado e armado na dialética entre o mesmo e o outro". No intenso jogo de imagens da sociedade contemporânea, essa força intempestiva de ausência de identidade seria justamente uma anti-imagem.

É de fato paradoxal que aquilo que impede o ato de nomear permita justamente um movimento de resistência ao processo de reificação do ser humano e do cidadão. Apropriando-me desse aspecto das reflexões de Castillo-Durante, intento mostrar como a ausência de nomes das personagens, associada à ausência de classificação da(s) narrativa(s), pode ser lida como esse movimento de resistência no cotidiano das grandes cidades, um movimento de sobrevivência das pessoas/ personagens e da própria literatura.

4. CASTILlO-DURANTE, 2004, p. 58. Tradução livre.

5. CASTILlO-DURANTE, 2004, p. 74. 
O livro começa com um cabeçalho "São Paulo, 9 de maio de 2000, Terça-feira", levantando a possibilidade de uma carta a ser escrita não se sabe a quem. Segue-se a previsão do tempo e a descrição do santo do dia, não por acaso, Santa Catarina de Bolonha, que "dedicou sua vida à assistência dos necessitados".

O livro, porém, não vai fazer a apologia dos pobres, defendendo sua causa. Trata-se de um jogo narrativo bem mais complexo e ambíguo, como se pode ver já pela frase em negrito do episódio seguinte "Mais neguim pra se foder", que introduz a questão da violência, embaralhando as vozes de diferentes segmentos sociais: os motoristas de carros caros, donos do rolex, das roupas e dos perfumes de griffe, e os passageiros dos ônibus ou os simples empregados; o barulho da música ou das balas de revólver "tum-tum-tum-tum-tum-tum-tum-tum" (p. 13). Percebe-se um movimento de interpenetração de grupos sociais diversos, sem possibilidade de se detectarem os agentes ou pacientes da violência social: os ricos que investem na bolsa, seus filhos, os decoradores, os traficantes, os delegados, os donos de boate, as garotas de programa, os leões de chácara.

Essa ambigüidade evidencia-se em dezenas de outros episódios, incrementada pela idéia de trânsito, já que vários relatos têm como cenário a estrada ou a rua. Tal cenário constrói-se pela estratégia de repetir e enumerar, muitas vezes sem pontuação, elementos semelhantes ou díspares, bem como pelo uso do paralelismo e/ou de outros recursos a acentuarem o fluxo contínuo da narração, paradoxalmente fragmentada. Veja-se, por exemplo, o episódio "Mãe", em que uma velha senhora viaja "grudada na poltrona número 3 da linha Garanhuns - São Paulo” (p. 16). Aí se confundem as necessidades - "a bexiga espremida' - os medos - "Meu Deus pra que tanta correria?", a paisagem - "as cercas de arame farpado, as achas, o capim, o cupim, carcaças de bois, urubus (...)", fazendo interpenetrar também os espaços do ônibus a se deslocar entre o nordeste e o sudeste e as vozes: a do imigrante pobre e a do autor implícito a desvelar os bastidores do processo de migração: Cuidado cuidado cuidado cuidado cuidado cuidado (p. 17).

A referência aos dejetos no ônibus:

o empesteado ar de janelas fechadas, vidros suados, no soalho, esparramados, papéis de bala, de bolacha, guardanapos, sacolas, palitos de picolé, copos descartavéis, garrafas plásticas, farelo de biscoito-depolvilho, de pão, de broa, farinha, restos de comida, pé de sapatinho de crochê azul-menino, noitedia (p. 16) 
ao lado da presença dos excrementos - "embora a bexiga espremida, embora o intestino solto" - ou aos urubus - "urubus, urubus, urubus" - introduz a escatologia, em seu significado duplo. No primeiro, liga-se a skôr, scatós, do grego, significando excremento. No segundo a éskhatos, também do grego, com a significação de extremo, último, o que conteria ainda a idéia de renovação, da possibilidade de um novo tempo. Daí, escatologia e cosmogonia estarem em relação constante, propiciando o tempo cíclico que marca o mito. ${ }^{6}$ No livro, porém, apaga-se, pelo menos em princípio, a idéia de renovação, já que o mito fragmenta-se em relatos miúdos e os rituais são deslocados e dessacralizados.

É interessante observar a relação do primeiro significado com outras significações de lixo, já que a presença desse elemento se intensifica com sua ocorrência em vários outros episódios. Lixo e morte se associam em nossa sociedade: o lixo é o resto, a sobra do que foi utilizado, mas também o corpo morto é uma forma de lixo, como acentua José Carlos Rodrigues. ${ }^{7}$ Além disso, na sociedade contemporânea, o mendigo, o habitante de rua, é, muitas vezes, colocado no mesmo nível do lixo de onde retira os recursos de sua sobrevivência. Não é sem razão que os relatos são atravessados por expressões como "quinquilharias camaleônicas" e "zés ninguéns"; gente e coisa não se distinguem. A esse respeito, a leitura do episódio "Ratos" pode ser esclarecedora. Misturada ao lixo do barraco e ao próprio cocô, a criança é ró́da pelos ratos que infestam a moradia:

Um rato, de pé sobre as patinhas traseiras, rilha uma casquinha de pão, observando os companheiros que se espalham nervosos por sobre a imundície, como personagens de um videogame. Outro, mais ousado, experimenta mastigar um pedaço de pano emplastrado de cocô mole, ainda fresco, e, desazado, arranha algo macio e quente, que imediatamente se mexe, assustando-o. No após, refeito, aferra os dentinhos na carne tenra, guincha. Excitado, o bando achega-se, em convulsões. (p. 20-21)

Observe-se que os ratos, a despeito dos guinchos, têm suas ações confundidas com a dos humanos: "observando seus companheiros", "se espalham nervosos", "Outro, mais ousado" experimenta mastigar...". Por outro lado, o bebê é apresentado pelos seus excrementos ou como um "corpinho débil, mumificado".

6. Estou me utilizando aqui de trecho retirado do artigo "In memoriam: escrita e lixo", escrito por mim e Maria Zilda Cury (2004)

7. RODRIGUES, 1995, p. 12. 
Ele e seus irmãos, animalizados, "se aninham"sobre um colchão de molas imundo. Suas ações não se distinguem daquelas dos ratos - "mordiscava"a chupeta suja. A história da família é contada com enumerações em que tempos e espaços, ações e reações se misturam: sobras recebidas dos outros, uma ida ao circo, a filha violentada pelo companheiro da mãe, a vingança e o incêndio provocado, o filho que sobreviveu ao pai ... A descrição da mãe engloba a degradação do ambiente e dos filhos:

Pensam, é fácil, mas forças não tem mais, embora seus trinta e cinco anos, boca desbanguelada, os ossos estufados os olhos, a pele ruça, arquipélago de pequenas úlceras, a cabeça zoeirenta. E lêndeas explodem nos pixains encipoados das crianças e ratazanas procriam no estômago do barraco e percevejos e pulgas entrelaçam-se aos fiapos dos cobertores e baratas guerreiam nas gretas. (p. 22)

Além disso, o sinal da resistência, que se traduz nas histórias contadas pela menina de onze anos embalando os sonhos dos irmãos e da mãe, dá-se lado a lado com mais uma relação sexual da mãe com "mais um nunca antes visto". Pessoas e animais não se distinguem na guerra pela sobrevivência, a não ser pelo sonho, pelo imaginário, que se mantém vivo nesse ambiente de morte.

No episódio "Chacina 41" repete-se tal situação, quando se apresenta o ponto de vista do vira-lata em busca de seu dono, um mendigo, e o das pessoas, com uma visão do baixo, de "valas fétidas e becos sonolentos". A pergunta que atravessa o texto - Por que fora agredido? - não se limita ao universo do cão agredido com um chute, antes extrapola-o, incluindo o que aconteceu com o dono e com os corpos perfurados de bala que o cão encontrara. Mais uma vez a narrativa embaralha elementos diversos, espalhando a contaminação da violência.: "O que exalava dos corpos era azedume de suor embaralhado ao doceamargo do medo" (p. 29). Espectador e cadáveres são colocados no mesmo nível, o do chão, junto ao lixo: "Lá ficou apenas o saco de estopa abarrotado de latas de alumínio macetadas" (p. 29).

No episódio "O evangelista" também instala-se a visão de baixo, ao rés do chão, quando ao cair, no meio da prédica para e por aqueles "invisíveis porque anônimos", o pastor, ele mesmo, cai na rua:

alguns segundos? minutos? um par de sapatos um par de tênis solas gastas aproximam-se bitucas folhas copos descartáveis pombos guardanapos palitos papéis de bala poça de mijo. (p. 59) 
No episódio "Natureza morta" narra-se a entrada da professora e dos alunos na sala de aula depois de um assalto. Na escola invadida misturam-se objetos escolares e cachimbos de crack; as plantinhas da horta são apresentadas como cadáveres, traduzindo com eficiência o título dado ao texto que, como um quadro, corrói o sentido adquirido na história da pintura, trocando-o por um sentido indicial, em um movimento contrário ao da linguagem, ou seja, o nome vira a coisa. Mas a natureza morta não é apenas a do quadro da descrição da horta, mais do que isso, é a natureza humana, restrita a um mundo como o observado e sentido pela professora: "as escandalosas casas de tijolos à mostra, esqueletos de colunas, lajes por acabar, pipas singrando o céu cinza, fedor de esgoto, um comichão na pálpebra superior esquerda e a solidão e o desespero" (p. 30).

No episódio "Assim:", a frase escrita, no corpo do texto, mas como que à margem - "a violência feia tão suja e perigosa" - concretiza esse movimento de contaminação, evidenciando que a violência não é responsabilidade daqueles que estão nas margens, mas parte do emaranhado social que a produz. Por isso mesmo, a exploração dos significantes das palavras, dos sinais gráficos, como parênteses e dois pontos deslocados, as frases cortadas, interrompidas, fragmentam o texto como a sociedade fragmenta seus grupos, ao mesmo tempo em que exibem a continuidade de ações e reações. A entrecortada conversa sobre guetos e violência entre pessoas da classe média reproduz e desloca valores e crenças de há muito repetidos, revelando, assim, que tal classe é também responsável pela violência social:

- não sou insensível à questão social irreconhecivel o centro da cidade hordas de camelôs batedores de carteira homens-sanduiche cheiro de urina cheiro de óleo saturado de a mão os cabelos raros percorre (minha mãe punha luvas, chapéu, salto alto para passear no viaduto do chá, eu, menino, pequenininho mesmo, corri na) este é o país do futuro? deus é brasileiro? Ontem um manancial hoje uma favela onde ontem uma escola hoje uma cadeia onde ontem um prédio do começo do século hoje um três dormitórios suítes setenta metros quadrados. (p. 37)

Não apenas os espaços se interpenetram, mas também o tempo. Passado, presente e futuro contam a história da cidade, ela própria uma história de exclusão social. Vozes diversas se cruzam no texto, apontando o ponto de vista daqueles que vêem os imigrantes - "baianos mineiros nordestinos" - como "gente desenraizada sem amor à cidade", ao lado da voz que vem como contraponto: "você e seus quatrocentos anos! Vão se". (p. 37). 
O texto desmanchado metaforiza a história desmanchada da cidade, que traz no lixo contemporâneo não apenas o que se costuma atribuir ao lixo, mas pedaços dessa ordem social excludente nos signos da riqueza e do poder, que insistem em permanecer acima do que consideram um país podre: as empresas, os ministros, as portarias assinadas, o heliponto. Não é por acaso que referências ao consumo e à publicidade ligados a datas comemorativas, sobretudo ao dia das mães, atravessam os contos. O rapaz que bate carteira para comprar um som para presentear a mãe; o pai observado pelo segurança quando compra/rouba fraldas para o filho recém nascido; a mocinha de tênis branco a olhar vitrines, seja a das lojas, seja a da TV e sua vida de modelos exuberantes; ao lado dos executivos de terno Armani, relógio rolex, telefones celulares, mercedes luxuosas desfilam na frente do leitor, sem as separações que se costuma ver na cidade. Ao lado disso, os sanduíches da Mc Donald associam-se à maconha e à cocaína, em seu trânsito que exibe pontas ocultas da meada.

Os sinais gráficos invertidos, deslocados, inadequados, atuam como sinais de trânsito descoordenados, desencadeando olhares interrogativos, que quebram a paisagem.

Vera da Silva Telles (2001), usando o conceito de paisagem utilizado por Flora Sussekind (1990), discorre sobre a naturalização da pobreza no Brasil, mostrando que esta é normalmente vista como cenário. Diz a socióloga:

Nessas formas de encenação pública, a pobreza é transformada em paisagem que lembra a todos o atraso do país, atraso que haverá de ser, algum dia, absorvido pelas forças civilizatórias do progresso. Paisagem que rememora as origens e que projeta no futuro as possibilidades de sua redenção, a pobreza não se atualiza como presente, ou melhor, na imagem do atraso, aparece como sinal de uma ausência.

Como paisagem, essa pobreza pode provocar a compaixão, mas não a indignação moral diante de uma regra de justiça, que tenha sido violada.

Embora a autora esteja falando de uma época anterior a que ora se analisa, sua reflexão é util para perceber que um movimento contrário a este é realizado no texto de Ruffato. 'Se, "transformada em paisagem, a pobreza é trivializada e banalizada" isentando-nos de responsabilidade individual ou coletiva, ao ser exibida

8. TELLES, 2001, p. 32 .

9. Ver que esse mesmo movimento se repete no livro Passaporte, de Fernando Bonassi, conforme já se demonstrou no capítulo "Flashes em circuito", do livro Corpus rasurado (WALTY, 2005) 
como paisagem através de um recorte textual, propõe o sentido oposto. Dito de outro modo: exibe-se a natureza de paisagem dos espaços vinculados à pobreza, levando-se a banalização às últimas conseqüências, de modo que ela irradie suas próprias fraturas alcançando o sistema que as gera.

A paisagem da cidade é caótica na medida em que acolhe tempos e espaços diversos; vozes dissonantes, hábitos e comportamentos comuns e/ou heterogêneos. No texto, as grandes personalidades exibidas pela mídia, associadas a instâncias decisórias, políticas e econômicas, são aproximadas dos anônimos "das prostitutas, dos meninos fumando crack, dos assaltantezinhos pés de chinelo" (p. 127). Isso porque tais personalidades também não são nomeadas, o que denuncia sua irresponsabilidade perante seus atos: "não posso declinar o nome dele, entende?, ele é muito conhecido, vira e mexe tem retrato dele no jornal, a cara dele aparece na televisão, (...)" (p. 107). Essas vidas, distantes no jogo político-social, se cruzam a despeito dos circuitos de helicoptéros e dos carros blindados, como se cruzam as palavras enumeradas sem vírgulas, as frases sem pontuação ou com pontuação alterada, os textos de origem vária e contaminada.

Por isso mesmo, o processo de anonimato que sustenta a construção da(s) narrativas(s) é, paradoxalmente, um processo de nominação, antireificação e resistência, com se intenta mostrar nesta leitura do livro. Nesse sentido, vale lembrar sua inserção no conjunto da obra do autor que o assina. É curioso que, depois de escrever, eles eram muitos cavalos, Ruffato, na escrita da trilogia Inferno provisório, proceda a um desmanche de livros escritos anteriormente, como que exibindo os bastidores da composição da narrativa urbana, em seu duplo sentido de texto e cidade. Ao misturar os textos de Histórias de remorsos e rancores (1998) e de Os sobreviventes (2000) a outros inéditos para compor Mamma, son tanto felice (2005), O mundo inimigo (2005) e Vista parcial da noite (2006), Ruffato como que mostra uma história de migração, do movimento entre cidades do interior e a capital paulista, mas, em um movimento inverso, fragmenta também a idéia de origem. O Beco do Pinto, espaço interiorano "gerador" de histórias várias, é desmanchado revelando a impossibilidade do retorno, ou mais do que isso a impossibilidade da origem. Na verdade, a cidade tem muitos becos que se cruzam labirinticamente, como o texto que se constrói e se desmancha em diferentes composições.

Propondo a mobilidade e o inacabamento, como projeto de escrita, Ruffato partilha com as personagens e com o leitor a autoria do(s) texto(s), mesmo que o nome na capa continue sendo o dele, com todas as implicações comerciais e jurídicas que lhe são inerentes. Isso porque, ao encenar um diálogo plural entre 
enunciações de lugares sociais divergentes, permeados pela contaminação escatológica dos cacos, seja dos produtos, seja dos textos, Ruffato monta uma história constelar, ${ }^{10}$ em que o excluído se faz presente sem ser assimilado, ou seja, não há intenção de se falar por ele. Vale lembrar a ausência, literal, da voz desse narrador, que desempenha antes a função de "mostrar".

Trata-se, pois, de um jogo entre anonimato e alterização, em que se faz um exercício de alteridade ensaiando o trânsito entre enunciado e enunciação; entre autor, personagens e leitores, na medida em que se utilizam gêneros discursivos diversos, deslocando-os, embaralhando-os. Quem é o autor da oração de São Expedito? E da previsão astrológica para o signo de Touro? Da lista de oferta de empregos ou dos livros de uma biblioteca particular? Do cardápio gastronômico que fecha o livro? A página em negro que se segue contém a resposta: todos nós ou ninguém. Ocorre, pois, uma explosão enunciativa que faz esbarrar vozes diversas em um movimento tensional que não se quer resolvido. Como no salto de tigre de Benjamin, dá-se um efeito de suspensão irremovível: a narrativa/cidade caótica habitada pela multidão anônima.

O texto em retalhos é como que montado com as sobras retiradas do lixo onde jaziam sem possibilidade da classificação que ordena e acalma. Ruffato devolve à sociedade aquilo que ela fabrica e rejeita, ao lado daquilo que ela elege como sua produção de qualidade. É a própria reprodução do inferno, como bem mostra John Scanlan, associando "lixo e inferno" (2005). O referido autor mostra que, paradoxalmente, na produção da arte contemporânea lugares como shopping malls, saguões de aeroportos e outros espaços de trânsito são também apresentados como espaços do inferno. Trata-se justamente daquilo que Marc Augé (1994) chama de "não-lugares". O jogo entre a esterilidade desse tipo de espaço e aqueles não assépticos, habitados por gente ligada ao escatológico meio da sujeira e dos excrementos explicita, na narrativa de Ruffato, a contaminação narrativa.

Essa narrativa contaminada e fragmentada é a narrativa possível, como aquela ligada às grandes catástrofes de que nos fala Benjamin ao referir-se ao fim da experiência e do conselho sobretudo no pós guerra (1987). Nesse sentido,

10. Cf. BENJAMin, 1987.

11. A este respeito, vale ver a dissertação "Imagens urbanas: uma leitura dos signos da cidade contemporânea nas narrativas de João Antônio e Luiz Ruffato, de Maria do Carmo Oliveira Moreira dos Santos (2002), em que se analisa essa função de mostrar a partir do conceito benjaminiano de alegoria, mostrando que a obra em sua materialidade enunciativa reflete as ruínas da paisagem urbana, desvelando uma história de sofrimento. 
seria marcada por "uma ambição paradoxal que parece guiar a procura literária e artística da geração mais contemporânea”, no dizer de Olinto e Schollhammer.

Paradoxal porque se compromete, por um lado, com o material histórico da realidade metropolitana e, por outro lado, encontra aqui, na violência, no erotismo e na miséria, o ponto cego da experiência que evade ou impede a representação, exigindo formas de expressão que evoquem a realidade enquanto efeito intrínseco do texto.

Nesse movimento, instala-se a resistência àquilo que Jurandir Freire Costa (2000) chama desinvestimento cultural, pois o fragmento de fala, como o fragmento de gênero discursivo, é a voz possível, gritos dissonantes. É a literatura possível em busca da linguagem que dê conta da heterogeneidade e da disjunção. No dizer de Marcelino Freire, ${ }^{13}$ um dos membros dessa geração, esta seria, mais que uma literatura da fala do outro, um ato de escuta do outro.

Trata-se justamente de um movimento contrário ao buscado pelo conhecimento na sociedade ocidental, como mostra Scanlan quando demonstra que a enciclopédia é fruto da necessidade de classificar e controlar, própria do homem de nosso meio. Discutindo o lixo como metáfora, diz Scanlan:

O lixo é a disformidade a partir da qual a forma alça vôo, o fantasma que assombra a presença. O lixo é as entranhas, os pedaços ou restos, o monte de matéria indistinguível que é, à sua maneira, originada de um repúdio resoluto; ele é o recusa-do (não aceito, negado, banido)

Ruffato faz o caminho contrário, pois, quando incorpora em seu livro os restos, revela que tais elementos são parte da ordem social que os fabrica, ou, mais do que isso, a ordem social é ela mesma feita de cacos, como bem mostra Scanlan, ao associar o lixo também à quebra do conhecimento: "O lixo concerne

12. OLINTO; SCHOLLhammer, 2002, p. 129.

13. Expressão utilizada pelo autor em conversa informal, em Ouro Preto, no dia $05 / 11 / 2006$.

14. Garbage is the formlessness from which form takes flight, the ghost that haunts presence. Garbage is the entrails, the bits or scraps, the mountain of indistinguishable stuff that is in its own way affirmed by a resolute dismissal; it is refuse-d (not accepted, denied, banished). (SCALAN, 2005, p. 14. Tradução livre.) 
ao equivocado; ele não nos conta nem uma coisa nem outra, mas apenas desmancha o status do nosso conhecimento do objeto mundo". ${ }^{15}$

E é justamente por construir seu texto como uma montanha de coisas/ pessoas aparentemente indistinguíveis, ou, de forma paradoxal, retirar essas pessoas/coisas da mistura em que se encontram, que Ruffato faz do anonimato condição de resistência, possibilidade de alteridade. Sua escrita, retomando outras que antes circularam, oscilando entre elementos antitéticos, deslocando sinais gráficos e regras de construção frasal, faz deslocar também o olhar do leitor, ele mesmo parte do cenário. Assim, novos olhares podem ser lançados sobre a história do país bem como à história da literatura brasileira, em um movimento entre passado, presente e futuro, o que demonstra que também essas histórias, inconclusas, estão em movimento. Como uma metonímia dessa e de outras histórias, instala-se a lista de livros, do segmento intitulado "Uma estante", onde figuram lado a lado, títulos de natureza vária, como Reunião, de Drummond e o Opoder infinito da mente, de Lauro Trevisan; As valkírias, de Paulo Coelho e Vidas secas, de Graciliano Ramos, sem contar os estrangeiros.

A mistura de livros, mistura de gêneros, a mistura de personagens, o hibridismo do anônimo se faz escrita a desafiar o olhar do leitor, ele mesmo, ao lado do autor, testemunha da catástrofe da história, como descrito por Benjamin, através da imagem do Angelus Novus, de Paul Klee: "onde nós vemos uma cadeia de acontecimentos, ele vê uma catástrofe única, que acumula incansavelmente ruína sobre ruína e as dispersa a nossos pés."

Nessas ruínas, "eles eram muitos cavalos", indistinguíveis, em sua marcha cega; eles são muitos cavalos no trânsito caótico da cidade, nas lacunas da escrita sem ponto final:

sacolejando pela Avenida Rebouças

o farol abre e fecha

carros e carros

mendigos vendedores meninos meninas

carros e carros

assaltantes ladrões prostitutas traficantes

15. Garbage relates to the equivocal; it tells us neither one thing nor another, but merely effaces the status of our knowledge of the object world. SCALAN, 2005, p. 16.

16. BENJAMIN, 1987, p. 226. 
carros e carros

mais uma

terça-feira

fim de semana longe

as luzes dos postes dos carros dos painéis eletrônicos

dos ônibus

e tudo tem a cor cansada

e os corpos mais cansados

mais cansados

a batata das minhas pernas dói minha cabeça dói e (p.96)

Résumé: Une analyse de l'ouvre eles eram muitos cavalos, (tant et tant de chevaux), de Luiz Ruffato, en son dialogue avec l'histoire de la littérature brésilienne, à partir du rapport entre l'anonymat, l'exclusion sociale, l'ordure et la vie urbaine.

Mots-clés: Anonymat, Exclusion sociale, Ordure, Vie urbaine.

\section{Referências Bibliográficas}

AUGÉ, Marc. Não lugares: introdução a uma antropologia da supermodernidade. Trad. Maria Lúcia Pereira. Campinas: Papirus, 1994.

BENJAMIN, Walter. Magia e técnica, arte e política: ensaios sobre literatura e história da cultura. Trad. Sérgio Paulo Rouanet. São Paulo: Brasiliense, 1987.

CASTILLO-DURANTE, Daniel. Les dépouilles de l'altérité. Montréal: XYZ éditeur, 2004.

COSTA, Jurandir Freire. Playdoier pelos irmãos. In: KEHL, Maria Rita (Org.). Função fraterna. Rio de Janeiro: Relume-Dumará, 2000. p. 7-30.

CURY, Maria Zilda e WALTY, Ivete. In memorian: escrita e lixo. In: Cerrados- Revista do Programa de Pós-Graduação em Literatura, n. 17, p. 55-60, 2003. (Literatura e globalização)

MEIRELES, Cecília. Romanceiro da inconfidência. Rio de Janeiro: Civilização Brasileira, 1972 .

MOREIRA, Maria Eunice. História da literatura e identidade nacional brasileira. Revista de Letras, n. 2, v. 43, p. 59-73, jul/dez. 2003. (Memória e literatura)

RODRIGUES, José Carlos. Higiene e ilusão. Rio de Janeiro: Nau, 1995.

RUFFATO, Luiz. eles eram muitos cavalos. São Paulo: Boitempo, 2000. 
RUFFATO, Luiz. Mamma, son tanto felice. São Paulo: Record, 2005. (Inferno provisório, V. I)

RUFFATO, Luiz. O mundo inimigo. São Paulo: Record, 2005. (Inferno provisório, v. II)

RUFFATO, Luiz. Vista parcial da noite. São Paulo: Record, 2006. (Inferno provisório, v. III)

SANTOS, Maria do Carmo Oliveira Moreira. Imagens urbanas: uma leitura dos signos da cidade contemporânea nas narrativas de João Antônio e Luiz Ruffato. 2002. Dissertação (Mestrado) - PUC Minas, Belo Horizonte.

SCANLAN, John. On garbage. London: Reaktion Books, 2005.

OLINTO, Heidrun Krieger; SCHOLLHAMER, Karl Erik. Novas formas de narrar na cena literária. Palavra: Revista do Programa de Pós-Graduação do Departamento de Letras da PUC-Rio, n. 9, p.101-134, 2002.

TELlES, Vera da Silva. Pobreza e cidadania. São Paulo: Editora 34, 2001.

WALTY, Ivete. Corpus rasurado. Belo Horizonte: Autêntica/PUC Minas, 2005. 